\title{
Unequal involvement, unequal attainment? A theoretical reassessment and empirical analysis of the value of motivation in the labor market
}

Johan Westerman, Swedish Institute for Social Research (SOFI)

\section{Johan.westerman@sofi.su.se}

\begin{abstract}
Inequality has often been explained by stable individual traits or by the structural features of labor markets. This study argues that we also should consider task involvement when we account for labor market inequality. Three mechanisms derived from experimental research link task involvement to performance: individuals involved in tasks are more focused on the work process, are more dedicated to mastery and problem-solving, and have stronger product quality perseverance. Despite the significance of task involvement as a motivation, its potential implication for labor market inequality is so far rather unacknowledged. We aim to develop its theoretical implications in the labor market context and test the expectation that task involvement is related to wage attainment by analyzing representative data for Sweden (LNU) and Europe (ESS). We theoretically locate our account within relational sociology, emphasizing that wage inequality is determined by interactions between worker attributes and the features of work organizations.
\end{abstract}

Keywords: Work motivation, task involvement, intrinsic motivation, wages, labor market inequality, labor market performance 


\section{Introduction}

This study argues that we should consider work task involvement, i.e. interest in conducting work tasks for no other apparent reason than the inherent enjoyment associated with it, when we account for labor market inequality. Inequality has previously often been explained by stable individual traits such as educational attainment, socioeconomic background and personality, or by the structural features of labor markets. ${ }^{1}$ Shifting the focus to motivation will tell us something of why workers with similar stable traits still end up with different outcomes on the labor market. This knowledge is important for the purpose of equalizing opportunities because task involvement can potentially be altered through comparatively rather simple means, such as worker-job match improvements.

The justification for considering task involvement is found in psychological research, which for centuries have argued that task involvement is a main driver of human motivation and exceptionally important for the performance of productive tasks. Based on a long line of empirical research, Cerasoli, Nicklin and Ford (2014) argue that individuals who find a task enjoyable to perform are more likely to put more of themselves into learning it, be better at finding solutions to problems associated with it, and persist longer and concentrate more when performing it. We will outline the implications of the link between task involvement and performance in the representative labor market context and discuss it in light of labor market

\footnotetext{
${ }^{1}$ The term inequality is not intended here to signal adherence to any specific normative perspective that would imply a sharp distinction between fair and unfair grounds for dispersion in rewards. Such a distinction, while important and relevant in principle, is hard to draw in practice and in any case beyond the purpose of the present paper. Our use of the term inequality is just an acknowledgement that dispersion in labor market rewards to at least some extent reflects unfair treatment, either in the sense that some individuals are rewarded below the level of their work performance or in the sense that some (perhaps many) individuals have been unfairly blocked from acquiring the resources necessary for high performance. This perspective thus implies that unfair treatment occurs and has real consequences for individuals, but does not attempt to identify precise boundaries or empirical criteria of such treatment.
} 
inequality theories, primarily human capital theory (Becker 1964; Mincer 1974) and the claimsmaking model (Avent-Holt and Tomaskovic-Devey 2014). Then we will test the generated expectation that task involvement is positively associated with wage attainment using representative Swedish and European survey data, and compare its predictive power with alternative explanations of inequality.

\section{Task involvement and performance}

Motivations are the reasons behind action, energy and persistence in goal-directed behaviors (Ryan and Deci 2000). Task involvement is motivation impelled by inherent curiosity in how particular work tasks linked together turn into finished products, how different work methods can be developed, and how skills useful in particular work processes can be applied and mastered (Nichols 1984). Task involvement has been singled out in research and theory as a sort of optimal motivation, because it originates from individuals' own valuing of their participation in the work process rather than external incentives (Csikszentmihalyi and Csikszentmihalyi 1992; Ryan and Deci 2000; Deci and Ryan 2014). ${ }^{2}$ Cerasoli, Nicklin and Ford (2014) locate three mechanisms in the empirical literature linking task involvement to performance. Individuals experiencing task involvement are (1) more concentrated on the task itself rather than outcomes of the task or other distractions; (2) give more of themselves and their abilities into learning,

\footnotetext{
${ }^{2}$ The term used in self-determination theory (Ryan and Deci 2000; Deci and Ryan 2014; Gagné et al 2015) is "intrinsic motivation" and the term used in (Csikszentmihalyi and Csikszentmihalyi 1992) is "flow". According to Eccles and Wigfield (2002), intrinsic motivation (as conceptualized in self-determination theory), flow, and task involvement can however be understood as describing a similar phenomenon. Intrinsic motivation is an ultimate need to discover the environment inherent in all organisms, flow (intense focus on mastering an activity) is an immediate reason to develop competence, while task involvement describes an individual's tendency to be motivated for intrinsic reasons in an achievement situation as opposed to peers who are motivated for external reasons (e.g. status and admiration). As such, task involvement best describes the phenomenon we aim to describe in the present study. By using the term task involvement, we also avoid conflation with various other applications of the term "intrinsic motivation" in social research. In the representative labor market context, we do however consider the three conceptualizations interchangeable and will use research from their respective (and other related) traditions in order to develop the argument, provide evidence and operationalize the concept we aim to analyze.
} 
thinking and coming up with ideas on how to perform; and (3) persist longer and tend to work with improving products others would consider good enough.

Above mechanisms have been observed in experimental manipulations of performance, effort and attitudes (e.g. Harlow 1953; Glucksberg 1962; Deci 1971; Kruglanski, Friedman and Zeevi 1973; Lepper, Greene and Nisbett 1973; Calder and Staw 1975; Ariely, et al. 2009; Mason and Watts 2010). The typical way of conducting such experiments is to offer a reward that logically should improve effort, performance and how much participants like doing a task. Generally, however, such rewards tend to act as disturbances rather than augmentations of these outcomes. The major exception to this pattern is for very simple and easily quantifiable tasks that offer no opportunities for discovery and learning, such as making the same product over and over again (Cerasoli, Nicklin and Ford 2014; Jenkins et al. 1998). There are few compelling explanations of this phenomenon except that individuals actually like to perform (particular) productive tasks for their own sake. ${ }^{3}$

Although the existence of task involvement as a motivation is evident, the magnitude of its effect on performance behavior is not fully known. Informed by the reductions observed in above experiments, we can yet assume that the true effect is significant. Descriptive evidence in an abstract statistical sense is also available in a few recent meta-analyses. Cerasoli, Nicklin and Ford (2014) found task involvement to be a medium to strong predictor of performance ( $\mathrm{r}=.35$ for qualitative tasks and .24 for quantitative tasks). Performance was measured either qualitatively, i.e. based on an evaluation of either a solution to a problem or a finished product; or quantitatively, i.e. a count of the number of solutions or finished products within a delimited

\footnotetext{
${ }^{3}$ See White (1959) for an early account of alternative explanations.
} 
time period. We make a similar interpretation of the findings in the meta-analysis by Nye et al.

(2012) that the influence of work interests on performance substantially increases when a specific work interest profile matches a specific work environment profile (from $r=.14$ to $r=.30$ for task performance as subjectively rated by supervisors, and from $r=.08$ to $r=.24$ for quantitative evaluations of performance). ${ }^{4}$

\section{Extending the scope to the labor market}

In human capital theory, individual productivity determines wage inequality. Individual productivity, in turn, is solely determined by individuals' skills materialized into performances at work. These skills are, beyond inherited endowments and education, formed through a learning process on-the-job (Becker 1964; Mincer 1974). ${ }^{5}$ A sociological relational perspective on how wage inequality emerges have a much broader scope in terms of what characteristics pay off in work organizations. Avent-Holt and Tomaskovic-Devey (2014) suggest that claims-making is a central feature of any organizational distribution of rewards (such as wages). All productive organizations have a pool of resources distributable to its members who make more or less legitimate claims on these resources (either latently or explicitly) depending on their possession of relevant characteristics, such as skills, credentials, motivation, asymmetric knowledge, and personality. In this section we focus on claims related to motivation, we will discuss alternative claims in section 7.

\footnotetext{
${ }^{4}$ Nye et al. (2012) analyze a very different research tradition, which has used the match between pre-defined interest profiles and the work environment as independent variable instead of observed/self-reported interest in particular tasks. Despite this difference, the theoretical model linking work interests to performance (through enhanced direction, vigor and persistence) in Nye et al. (2012) is strikingly similar to the present theoretical argument. ${ }^{5} \mathrm{~A}$ common human capital equation assumes exogenous endowments and predicts wage attainment with years of attained education and years of work experience as proxies for human capital, and tends to explain a significant part of wage differences in the labor market (see Lemieux 2006 for a review of research utilizing this model known as the Mincer wage equation).
} 
Task involvement may constitute a reason for claims-making through two basic channels. First, we argue that task involvement generates work performance. Performances and contributions to the organization are of course in themselves relevant claims, in line with both the claims-making model and human capital theory. Second, we argue that task involvement is important for learning and that learning is crucial for how skills are formed at work. By combining research on task involvement and human capital theory, task involvement can hence be thought of as significant fuel for learning processes at work, and the skills formed through this process may in a second step be used as a reason for making claims on organizational resources, such as wages.

The two channels may seem similar in effects yet are distinct in a temporal sense. The first is expected to work directly on the productivity-wage relationship, while the second may only have a delayed positive effect because the accumulation of skills is arguably not a valid claim before it has been realized into a productive value. For the present purpose, distinguishing the influence of task involvement in a temporal sense is however of minor practical importance.

One question regards why employers do not exploit particular (extra) performance generated by task involvement and keep the added value for themselves; if workers perform for their own enjoyment why would they make claims on the added value? One reason may be organizational norms suggesting that individuals should get an equal amount of pay for an equal amount of performance. If these norms are not honored it could be perceived as insulting and lead to a termination of the employment relationship or some other form of retaliation (such as in the argument made famous by Akerlof 1982, however, based on previous sociological contributions such as Homans 1954). The probable existence of such norms in most work organizations explains why workers motivated by task involvement would not perform at their maximum level (or resign) if they received wages that did not match their productivity. 
Another interesting feature of task involvement in the labor market context is related to the fact that many work-life decisions have long-term consequences, encouraging individuals to be foreseeing when making such decisions. An apparent risk, due to the increased uncertainty associated with any decision regarding the distant future, is that individuals feel unmotivated by the work tasks they thought they would feel motivated by when they finally have entered work life. To some extent, individuals may of course learn about their motivations before they enter work life from the practice of tasks that resemble those they later will face. Individuals may also, at least for a while, try out different jobs in order to learn about what motivates them, i.e. a form of “job-shopping” (cf. Johnson 1978). To another extent, the link between task involvement and performance is unpredictable for individuals, because they cannot evaluate particular work tasks before they experience them. Individuals hence need to engage in a job search process on the labor market in order to find the kind of work that motivates them, with unknown and perhaps unequal outcomes (cf. Jovanovic 1979).

Although the uncertainty associated with task involvement is problematic from a strict rational choice perspective, we argue that it makes the topic more interesting to consider because it strengthen its position as an additional dimension of inequality that previous explanations cannot account for. Uncertainty may explain why wage differences related to task involvement occur between two individuals in the same objective circumstances, such as in the situation when both of them anticipate success in a particular occupation but one actually lacks the fundamental motivation to succeed. We can also, conversely, think of individuals who make a work life decision without anticipating either task involvement or related wage attainment yet end up experiencing both. Uncertainty can also yield wage differences related to task involvement if individuals get distracted by other incentives (e.g. status and wages) they associate with 
uninvolving kinds of work. If individuals were certain about exactly how negative a response to such incentives would be for their later experiences of task involvement (including related and similarly unknown outcomes), they would probably take this information into consideration before responding.

\section{Task involvement and autonomy}

The effect of task involvement is not independent of general attributions of the work environment. Indeed, much research has focused on how to undermine the effect of task involvement by using other incentives as distractions. This research has shown that task involvement is least potent under the following two (related) conditions: (1) pay that is directly linked to the completion of tasks or products (cf. piece-rate wage pay systems in the labor market); (2) tasks that are very simple and easy to quantitatively evaluate (Jenkins et al. 1998; Cerasoli, Nicklin and Ford 2014). The two conditions are related because pay directly linked to the completion of products is only practical if the number of finished products is countable. In Cerasoli, Nicklin and Ford (2014), task involvement is defined by the match between the individual and the task, while performance (all else equal) is a function of task involvement and the situational definition of performance, i.e. whether it is quantitatively or qualitatively evaluated and/or rewards are directly linked to the completion of clearly specified tasks or not.

Performance pay and quantitative evaluations of performances are however uncommon in modern labor markets (see footnote 10). Nevertheless, jobs still differ in terms of work conditions. Worker autonomy, i.e. the amount of control individual workers have over how to perform their assigned work tasks, has for a long time been regarded as a work condition particularly favorable for performance related concepts (such as work learning, well-being and 
job satisfaction) in sociological labor market theory and research (e.g. Appelbaum et al. 2000; Gallie 2013; Inanc et al. 2015). Worker autonomy is similar to the concept of self-determination, considered important in research on task involvement (Deci and Ryan 2014), and therefore provides an important link between this research and the sociology of labor markets.

We find it plausible to expect that a work organization that at least to some extent values worker initiatives, i.e. autonomy, participation and self-determination, is a condition that should strongly induce the prospect of task involvement being turned into an actual productive contribution. For instance, not even the most involved workers can be expected to be able to improve the work process or develop new methods to any significant extent if such behaviors are highly discouraged by the management. At the very least, even if such workers are able to make improvements despite management opposition, they are unlikely to be rewarded for it. On the other hand, we also find it hard to believe that managerial interventions alone directly can create task involvement to any significant extent if the workers do not find the work process interesting to begin with. Enhanced autonomy may arguably even be detrimental for performance if workers are mainly driven by motivations external to the work process. Therefore, we argue that the interaction between how interesting workers find the work process and the degree to which they are allowed to influence it is most crucial for performance outcomes and rewards linked to task involvement. (However, we do not rule out that certain work conditions also directly may depress or maintain task involvement; more on this in section 7.) We hypothesize that worker autonomy amplifies the association between task involvement and wage attainment. 


\section{Summing up}

This study argues that we should consider task involvement when we account for labor market inequality. Three consequences of task involvement: (1) work activity focus, (2) dedication to mastery and problem-solving, and (3) product quality perseverance, lead workers motivated by task involvement to perform better at work. Under the assumption that differences in performance are reflected in wage differences, we expect performances generated by task involvement to pay off in higher wages. Thus, in the representative labor market context, we hypothesize that there is a positive association between task involvement and wage attainment. Additionally, we expect worker autonomy to amplify the positive association between task involvement and wage attainment.

\section{Data and methods}

The Swedish Level-of-Living survey (LNU) is a nationally representative survey which has been conducted six times since 1968. A great strength (for the present purpose) of the most recent LNU (2010) is the unusual ${ }^{6}$ inclusion (in inequality research) of measures of work motivation, along with a rich set of variables designed to test major implications of common inequality theories. The European Social Survey (ESS 2010) includes the same measures of work motivation and will be used as an auxiliary dataset in order to evaluate the main findings with an additional data source and extend the scope beyond the Swedish context. LNU is however

\footnotetext{
${ }^{6}$ Note here the distinction between the concept of motivation, defined as the reasons behind actions, and the concept of values, which is more common in sociological survey research. Generally, values are defined as "(a) concepts or beliefs, (b) about desirable end states or behaviors, (c) that transcend specific situations, (d) guide selection or evaluation of behavior and events, and (e) are ordered by relative importance” (Scwartz and Bilsky 1987, p. 551). (b) and (c) clearly distinguishes values from motivation as a concept. (b) can regard distant goals and does not necessarily constitute reasons for current actions. (c) is another delimitation that does not apply to motivation (which can be highly situational). Hence, values can but do not necessarily constitute motivations.
} 
preferred over the ESS because of its longitudinal design, its richer set of control variables, its

larger within-country sample, and its better measure of hourly wage.

The 2010 wave of LNU has 4,415 respondents who were interviewed by Swedish Statistics (the government statistics department) in 2010 and 2011. We analyze only employees which excludes 1724 individuals. Additionally, in order to ensure that all respondents have at least some substantial work experience (otherwise it would not make much sense to analyze what motivates them at work), only individuals above the age of 30 are included in the sample. For the same reason, respondents who did not work around the time when the previous LNU was conducted in $2000,{ }^{7}$ or work below 20 hours per week in 2010, are excluded. Finally, we exclude all respondents with a missing value on the dependent variable or who were older than the traditional retirement age in Sweden of 65 at the time of the survey. The final analytical sample consists of 1891 employees. Missing values in the independent variables have been imputed using multiple imputation. ${ }^{8}$

\footnotetext{
${ }^{7}$ In order to assure that also those respondents who did not participate in the survey 2000 actually worked in 2000, we used register data on income from work that year and removed 227 individuals with zero or missing registered income from work.

${ }^{8}$ Additional datasets are generated which contain predicted values of the missing value from regression equations with all other included variables (and higher order terms) as predictors. A random component from a standard normal distribution is added to each regression equation in order to simulate a random component in the equations. Means and covariances are then randomly drawn from the distribution of means and covariances formed by the datasets, and these are used to impute the missing values all over again. This procedure is repeated until the imputation model converges and standard errors reflect the loss of information associated with the missing values. Regression parameters are then drawn from a final distribution of 20 generated datasets. The procedure is conducted using the Markov-Chain Monte Carlo algorithm (MCMC) (Allison 2001) implemented in STATA 13 (StataCorp 2013). Individuals with missing value in the dependent variable are included in the imputation model and erased afterwards in accordance with Von Hippel's (2007) recommendation. The imputation model is estimated using information from all other included variables plus age and age squared and the same imputation model is used for all the conducted analysis on LNU data (except the model with an alternative measurement of task involvement which has its own imputation model with the same variables included). Multiple imputation relies on the assumption that the incidence of missing values in a particular variable is missing at random (MAR), conditional on all other included variables (Allison 2001). This assumption is not testable, but casewise exclusion of individuals with missing values instead of multiple imputation was conducted in order to check the potential influence of the imputation procedure on the main findings of the study. Results (see table A.5 in the appendix) show that estimates are substantially similar to the imputed models. In order to be able to correctly estimate the LDV model without
} 
The ESS sample is, as far as possible, defined in accordance with the LNU sample. The analytical sample size consists of 6296 employees from all of the participating countries (in total 27).

Descriptive statistics for both data sets are included in tables A.1a and A.1b in the appendix.

\subsection{Dependent variable}

The dependent variable in the analysis based on LNU data is hourly wage, which has been computed from wage reports reported in accordance with the unit count specified on the employment contract (e.g. monthly or per hour): "How large is your [monthly/hourly/etc.] pretax wage for the work hours you usually work with fixed [monthly/hourly/etc.] wage?” If several wage forms have been reported they have been combined and converted into hourly units. Workers who had a wage below 70 or above 500 Swedish kronor (SEK) were given the value 70 and 500 SEK respectively, due to scarce distributions of observations at these levels (16 cases above 500 and 8 cases below 70). The dependent variable was further transformed into its natural logarithm, in order to get proportional estimates. A lagged dependent variables (LDV) was retrieved from the previous LNU survey in 2000.

In the ESS, hourly wage was computed from two variables: reported salary (in/converted to Euros) and a variable measuring the unit count of the salary report. The exact questions were: “What is your usual gross pay before deductions for tax and insurance?” and "How long a period does that pay cover?” In order to achieve similarity with the measure in the LNU, the variable 
was also transformed into its natural logarithm and workers who earned below 7 and above 50 Euros per hour were given the value 7 and 50 Euros respectively.

\subsection{Independent variable}

Task involvement in both the LNU and the ESS was computed from the question: "People put effort into their work for many different reasons. Which of the reasons shown on this card is the main reason why you put effort into your work?” Response alternatives include: (1) to be satisfied with what I accomplish, (2) to keep my job, (3) because my work is useful for other people, (4) to get a higher wage or a promotion, (5) because my work tasks are interesting, (6) because it is everyone's duty to always do their best. The respondents were requested to give one primary and one secondary reason, in order of personal importance (ESS 2010; LNU 2010).

The answer (5) “interesting work tasks” is the only one that can be conceptualized as task involvement (cf. Gagné et al. 2015). Most of the other motivations have to do with the respondents’ fulfilments of personal, ideological and status values. The main distinction being made is therefore between workers with "interesting work tasks" (as main or secondary work motivation) and all others.

We recognize that individuals may have multiple reasons to conduct effort at work and that task involvement may be a useful motivation even though it is not the individual's main reason. By asking for both the main and the secondary reason we reduce the risk that we miss individuals who actually make an effort at work because they find it interesting although it is not their main reason. Another attractive trait of the operationalization is that most of the other answers are more or less socially desirable (with the main exception “to keep my job”). In order to test whether selection into less normatively correct answers remains and drives the results, we also 
used an alternative measurement strategy consisting of six scores representing the six motivations, constructed by taking the value .5 for secondary motivation and 1 for main motivation. We have implemented this measure in a supplementary analysis (see appendix A.4), which shows that the association between task involvement and wage attainment is substantial regardless of the reference motivation (although there are some variation in the sizes of the differences).

\subsection{Interaction variable}

Worker autonomy was measured with the mean of two items ranging 0 - 4: "To what extent do you have influence over what tasks you carry out?" and “To what extent do you have influence over how you carry out your tasks?” Alpha equals .74 in the analytical sample.

\subsection{Analytical strategy}

We use OLS regression analysis in order to estimate the association between task involvement and wage attainment. A regression estimates a focal association for individuals with the same value on all included independent variables. We aim through this approach to come closer to an understanding of how strong the effect of task involvement on wage attainment is in the representative labor market, but recognize that a confident estimation of such effect is beyond the capacity of the present and any currently available data set. Yet, it is still important to elaborate the assumptions that would need to be fulfilled if the estimated associations were to be interpreted as effects, and, given our data and methods, discuss how plausible they are in the representative labor market context. 
A first assumption states that task involvement is an independent and significant positive factor of work performance behavior. We argue that the fact that rewards which logically should improve performance behavior rather tend to act as disturbances provides significant proof for considering this assumption plausible (see section: Task involvement and performance).

A second assumption states that the causal chain linking performance and wage attainment goes from performance behavior (through productivity) to wage attainment (and not the other way around). The assumption is standard in human capital theory although of course open for debate more generally. For instance, research suggests that firms paying higher wages are more productive (see the meta-analysis by Peach and Stanley 2009). ${ }^{9}$ Yet, in a general sense, Williams, McDaniel and Nguyen (2006) have shown, through a meta-analysis of work place studies, that pay satisfaction practically has a very weak positive relationship with work performance $(\rho=.05)$. The estimates that generate the relationship to a large extent regard work places applying performance pay, which we already know is associated with reversed causation (see e.g. Cerasoli, Nickling and Ford 2014). In more particular circumstances (e.g. tasks involving complex problem-solving), unusually high and unmotivated pay levels have even been proven negative for performance, either because they make individuals overrate their own value and hence decrease their effort (Mason and Watts 2010), or because overvalued individuals choke under the pressure to perform beyond their ability (Ariely et al. 2009). A recent study by Jirjahn (2016, p. 510) also "finds no evidence that performance pay per se or a high-wage policy per se has an influence on productivity. However, combining performance pay with a high-wage policy significantly raises productivity.” Taken together, above research suggests that reversed

\footnotetext{
${ }^{9}$ The exact mechanism generating this relationship is not observed however. For instance, employers may use a high wage policy in order to attract and keep better abled and motivated workers. See Akerlof and Yellen (1986) for a review of theoretical explanations of this relationship, the so-called efficiency-wage relationship.
} 
effects of (high) wage levels on performance are limited to the (related) conditions: easily

quantifiable work performance and explicitly set performance pay. Since we presumably observe mainly qualitative evaluations of performances in the representative labor market context, ${ }^{10}$ we consider assumption 2 plausible.

A third assumption is that self-reported task involvement as measured in this study reflects task involvement as observed in the experimental literature on task involvement. This assumption (of no measurement error) may be perceived as problematic in quantitative research on subjective concepts. Yet, we aim to capture in this study the reasons behind individual work actions and there are, as far as we can imagine, no better way of capturing these reasons in a representative study than actually asking survey respondents about them. Experimental research applying both self-reported and directly observed measures of task involvement has also tended to find that the same mechanism governs both (Deci, Koestner and Ryan 1999).

A fourth assumption is that included control variables are correctly measured and specified and cover all alternative explanations of the focal association. We have carefully chosen control variables that could influence both task involvement and wage differences from the literature on inequality. Indeed, the LNU is designed for analyzing the most common explanations of inequality. Of course, however, we do recognize that it is difficult to explicitly account for all imaginable alternative explanations. Generally, we have balanced the inclusion of control variables considering both the assumption above and the risk that controls are located

\footnotetext{
${ }^{10}$ In the LNU sample, 0.10 percent work under an individually set piece-rate system and 0.85 percent under a team based piece-rate system. Additionally, 5.65 percent receive at least some part of the salary in the form of bonuses (without reference to whether it is conditional on performance or not). Among those receiving any kind of explicitly set performance pay, we do not know how many get pay incentives set above the market price of their skills and motivation. Yet, since the pool of possible such cases is so small we are rather confident their influence can only be marginal for the estimates in this study.
} 
downstream in the causal chain of events (i.e. subsequent to task involvement). Next, we present and theoretically justify the inclusion of control variables.

\section{Alternative explanations of wage inequality}

First, gender is a supposedly important factor influencing the relationship between work motivations (in a general sense) and wage attainment (for instance women being more motivated by pro-social ideologies, see e.g. Folbre 2012). Since this is not our primary topic (a thorough analysis would require its own study), we only account for gender in the statistical analyses by estimating all models separately by sex (with the exception of the interaction model with worker autonomy, in which we pool samples in order to increase statistical power).

Second, as previously argued, human capital accumulation at work may be strengthened by task involvement. However, work experience (and education) may also constitute investments that open up opportunities for individuals to work in jobs they find interesting and enjoyable, and of course they provide reasons for making claims on organizational resources such as wages. Therefore, we account for education and work experience (accumulated self-reported years) in the analysis. For exact operationalization see table $1 \mathrm{a}$.

Third, ambitions transmitted from the family background to achieve education and status have been viewed as important for inequality outcomes (Parsons 1940; Hyman 1953; Haller and Portes 1973; Spenner and Featherman 1978). Such ambitions may arguably be detrimental for later experiences of task involvement because they may constrain individuals to occupational choices encouraged by their families instead of their interests. On the other hand, studies have shown that also self-directedness is encouraged to a larger extent within the middle class than within the working class (Kohn and Schooler 1983). Self-directedness is potentially positively 
related to task involvement since it can set individuals on a course toward attaining work they like to conduct rather than to focus on alternative rewards favored by the social environment. All the same, we account for social class background indicated by the parents’ occupational status and measured with the Standard International Occupational Prestige Scale (SIOPS) (Ganzeboom and Treiman 1996). The highest available status score for either the father or the mother is used.

Fourth, (some) personality traits constitute important positive predictors of wage differences over and above family background and education (Goldsmith, Veum and Darity 1997; Nyhus and Pons 2005; Drago 2011; Lindqvist and Vestman 2011; Heckman and Kautz 2012; Shanahan et al. 2014), in one sense because they constitute "soft” skills (Heckman and Kautz 2012), however, perhaps also because persuasive and outgoing personality traits may be utilized in wage negotiations. Since work motivations in general and task involvement in particular potentially could be influenced by the personality of individuals, such as general vitality and openness to experience, we incorporate personality through the big-five factor personality model (following conventions in e.g. Nyhus and Pons 2005; Shanahan et al. 2014). For operationalization, the 10-item version developed in Rammstedt and John (2007) is utilized, including items measuring agreeableness, conscientiousness, extraversion, neuroticism and openness to experience. For exact operationalization see table $1 \mathrm{a}$.

Fifth, many explanations of wage inequality are related to occupational class and positional power. Skill requirements of jobs are highly determining of wage differences (Le Grand and Tahlin 2013), and the complex types of work associated with tasks demanding advanced skills offer opportunities to utilize task involvement for productive purposes. Another key factor is supervisor responsibilities, which most often is associated with a wage premium, and Kalleberg and Griffin (1978) also show that employees who are not managers tend to experience work as 
less interesting. Another potential alternative explanation is asymmetric knowledge possessions within work organizations. Monitoring difficulties and the possession of scarce and organization specific knowledge are expected to lead to stronger employment relations (Goldthorpe 2000), and potentially also to possibilities to change the work content (e.g. to ignore uninteresting tasks). Asymmetric knowledge possessions favoring the employees may also augment their claims on both wage rewards and allocations to work tasks they desire to conduct. We account for above class dimensions in the main analysis, although they to some extent may control a part of the association we aim to estimate (i.e. selection into jobs based on differences in task involvement). For theoretical validations of the measures, see Le Grand and Tahlin (2013) and Tahlin (2016). For exact operationalization see table 1a.

Sixth, as previously discussed, some general work conditions, e.g. those encouraging autonomy, participation, and self-determination, may enhance the expression and long-term maintenance of task involvement. A common sociological argument is that these conditions, as well as high wages, cluster in certain occupations, jobs and organizations (Appelbaum 2000; Bauer 2005; Gallie 2013; Inanc et al. 2015). Although we can directly account for aspects of these conditions through the use of explicit control variables (see above paragraph as well as section 6.3.), we can also use methods that indirectly control for such clustering of favorable work conditions. In two sensitivity analyses, we include a lagged dependent variable (LDV) (Angrist and Pischke 2009) and occupational fixed effects, in total 25 dummy variables measured at the International Standard Classification of Occupations 1988 edition's (ISCO-88) two-digit level. However, by including these additional controls we also risk eliminating parts of the effect we aim to estimate, i.e. we eliminate selection into occupations and jobs based on task involvement. Due to the 
added complexity involved with the interpretation of these models, we will discuss them further in section 8.4 .

\section{Results}

\subsection{Main results}

Tables $1 \mathrm{a}$ and $1 \mathrm{~b}$ show the main results, stratified by gender. As expected, workers who are motivated by task involvement have higher wages than workers motivated for other reasons. As shown in model 1, which included no other independent variables than task involvement, men motivated by task involvement have about 17 percent higher wages compared to men motivated for other reasons. Women, similarly, have about 10 percent higher wages if they are motivated by task involvement. ${ }^{11}$ In model 2 , we introduce control variables measuring parent’s occupational status and individual personality characteristics. The association between task involvement and wage attainment is slightly reduced in this model, yet still substantial and significant. In model 3, we introduce the human capital variables, again slightly reducing the association between task involvement and wage attainment. In model 4, we introduce indicators of occupational class and other positional traits. Again, the association between task involvement and wage attainment is slightly downward adjusted. However, task involvement still accounts for large wage differences in the labor market. Men motivated by task involvement have on the average about 9 percent higher wages than men motivated for other reasons. The 95 percent confidence estimate for the population is 5 to 13 percent. Women motivated by task involvement

\footnotetext{
${ }^{11}$ One explanation of the weaker effect for women could be that women are generally paid less in accordance with their performance, which, in that case, also should affect their returns to task involvement. Another reason could be the fact that women's wage distribution is more compressed, resulting in smaller wage differences between women in general. In order to check whether the latter is the case we compute wage percentiles (within the sexes) and rerun the analysis (not shown), which reveals that the weaker effect for women is present even if we regress wage percentiles.
} 
have on the average about 6 percent higher wages than women motivated for other reasons. The 95 percent confidence estimate for the population is 4 to 9 percent. The differences are large considering that they regard individuals with similar skill credentials in the same type of jobs. ${ }^{12}$ Employers clearly tend to value employees motivated by task involvement to such an extent that they do not tend to replace them with other employees willing to work for a substantially lower salary. In conclusion, task involvement is, as hypothesized, a durable predictor of wage attainment. How durable in comparison with alternative explanations of wage inequality, is a question we turn to next.

Table 1a. Regression of logged hourly wage on task involvement. For men

\begin{tabular}{lcccc}
\hline & M1 & M2 & M3 & M4 \\
\hline Task involvement & 0.17 & 0.15 & 0.13 & 0.09 \\
& $0.13,0.21$ & $0.11,0.19$ & $0.09,0.17$ & $0.05,0.12$ \\
Parents' SIOPS & & & 0.00 & 0.00 \\
& & 0.01 & $0.00,0.01$ & $0.00,0.01$ \\
Agreeableness & $0.00,0.01$ & -0.01 & -0.02 \\
Conscientiousness & 0.00 & $-0.04,0.02$ & $-0.05,0.01$ \\
& $-0.03,0.04$ & 0.01 & 0.00 \\
Extraversion & 0.01 & $-0.02,0.04$ & $-0.03,0.03$ \\
& & $-0.02,0.04$ & 0.04 & 0.04 \\
Neuroticism & 0.04 & $0.01,0.06$ & $0.02,0.06$ \\
& & & -0.01 & 0.00 \\
Openness & & & $-0.03,0.02$ & $-0.03,0.03$ \\
& & -0.01 & -0.02 & -0.02 \\
Years of schooling & $-0.04,0.02$ & $-0.04,-0.00$ & $-0.04,-0.00$
\end{tabular}

\footnotetext{
${ }^{12}$ In 2010, average apartment rents in Sweden were 4,621 SEK for two rooms and 5,633 SEK for three rooms. For men, the estimated average wage difference related to task involvement for a salary of 25,300 SEK (the total median in 2010) is 1,594 SEK (net of a tax rate of 30 percent), which is substantially more than the average difference between the rent for a two room and a three room apartment for that year (data source: Swedish statistics).
} 
Work experience

$\begin{array}{cc}0.02 & 0.02 \\ 0.02,0.03 & 0.01,0.03\end{array}$

Work experience

$-0.00$

$-0.00$

squared

$-0.00,-0.00$

$-0.00,-0.00$

Skill requirements

0.04

$0.03,0.05$

Authority

0.00

$0.00,0.00$

Organizational

0.02

importance

$0.00,0.04$

Monitoring

$-0.00$

difficulties

$-0.02,0.01$

\begin{tabular}{lcccc}
\hline$R 2$ & 0.06 & 0.13 & 0.26 & 0.36 \\
\hline$N$ & 975 & 975 & 975 & 975 \\
\hline
\end{tabular}

95\% confidence intervals in second row.

Data: The Swedish Level-of-Living survey 2010.

Operationalization of control variables: Social class background is measured with the parent's highest available SIOPS value (Ganzeboom and Treiman 1996); Personality is measured with 10 items ranging 1 (disagree), 2 (disagree a little), 3 (neither agree nor disagree), 4 (agree a little), 5 (totally agree). Agreeableness is measured with the mean of the items "I am generally trusting" and "I tend to find fault with others" (reversed), Conscientiousness is measured with the mean of the items "I tend to be lazy" (reversed) and "I deal with tasks thoroughly", Extraversion is measured with the mean of the items "I am reserved" (reversed) and "I am outgoing and sociable", Neuroticism is measured with the mean of the items "I am relaxed and handle stress well" (reversed) and "I get nervous easily", Openness to experience is measured with the mean of the items "I have few artistic interests" (reversed) and "I have an active imagination" (Rammstedt and John 2007); Human capital is measured with the questions "How many years altogether have you been to school or vocational training full-time? (Include all education from elementary school on.)" and “Approximately how many years altogether have you spent in gainful employment?”. They are included as separate indicators and with an additional squared term for experience; Skill requirements are measured with the questions "Is any schooling or vocational training above elementary schooling necessary for your job?" and "About how many years of education above elementary school are necessary?"; Supervisor responsibilities are measured with the question "How many persons do you supervise?”; Knowledge asymmetries are measured with the questions "How difficult or easy do you think it is for your immediate boss to know how much effort you put into your work?" and "In your opinion, how difficult would it be for your employer to replace you if you quit?" Both range from 1 (very easy), 2 (fairly easy, 3 (not particularly difficult), 4 (fairly difficult), to 5 (very difficult) and are included as separate indicators.

Table 1b. Regression of logged hourly wage on task involvement. For women

\begin{tabular}{lcccc}
\hline & $\mathrm{M} 1$ & $\mathrm{M} 2$ & $\mathrm{M}$ & $\mathrm{M} 4$ \\
\hline Task involvement & 0.10 & 0.08 & 0.07 & 0.06 \\
& $0.06,0.13$ & $0.04,0.11$ & $0.04,0.10$ & $0.02,0.09$ \\
Parents' SIOPS & & & & \\
& & 0.01 & 0.00 & 0.00 \\
& & $0.00,0.01$ & $0.00,0.00$ & $0.00,0.00$
\end{tabular}


Agreeableness

Conscientiousness

Extraversion

Neuroticism

Openness

Years of schooling

Work experience

Work experience

squared

Skill requirements

$\begin{array}{ccc}-0.03 & -0.03 & -0.02 \\ -0.06,0.00 & -0.06,-0.00 & -0.05,0.00\end{array}$

$-0.01$

$-0.03,0.02$

$-0.00$

$-0.03,0.02$

$-0.01$

$-0.03,0.02$

0.02

$-0.01,0.04$

0.01

0.00

$-0.01,0.03$

$-0.02,0.03$

$-0.02$

$-0.04,0.00$

$-0.01$

$-0.01$

$-0.03,0.01$

$-0.03,0.01$

$-0.01$

$-0.03,0.01$

$-0.03$

$-0.02$

$-0.04,-0.01$

$-0.04,-0.00$

$$
0.03
$$

0.01

$0.03,0.04$

$0.01,0.02$

0.01

$0.00,0.01$

0.01

$0.00,0.02$

-0.00
$-0.00,0.00$

$-0.00$

$-0.00,-0.00$

0.03

$0.03,0.04$

Authority

0.00

$0.00,0.00$

0.01

$-0.00,0.03$

$-0.01$

$-0.03,-0.00$

Monitoring

\begin{tabular}{lcccc}
\hline$R 2$ & 0.03 & 0.10 & 0.22 & 0.31 \\
\hline$N$ & 916 & 916 & 916 & 916 \\
\hline
\end{tabular}

95\% confidence intervals in second row

Data: The Swedish Level-of-Living survey 2010

For control variables see Model 4 in Table 1a 


\subsection{Comparison with alternative explanations of wage inequality}

The control variables function to purify the association between task involvement and wage attainment. They may also constitute alternative reasons for making claims on organizational wage resources, however. As such, they are interesting to compare with task involvement in order to get a sense of the relative importance of the latter. In order to achieve this, we perform a decomposition of the explained variance using the r-squared statistic (r2). We divide the independent variables incorporated in Model 4 into seven blocks and analyze total r2 (hence disregarding underlying confounders) and unique r2 (hence disregarding mediated effects) explained by each block. ${ }^{13}$ The seven blocks are: (1) task involvement, (2) social class background (parent’s occupational status), (3) personality (Big-five), (4) human capital (education, work experience, work experience squared), (5) skill requirements, (6) supervisor responsibilities, and (7) knowledge asymmetries (monitoring difficulties and organizational importance).

Table 2. Total and unique contributions of various explanations of wage inequality

\begin{tabular}{|c|c|c|c|c|}
\hline & \multicolumn{2}{|c|}{ Men } & \multicolumn{2}{|c|}{ Women } \\
\hline & Total & Unique & Total & Unique \\
\hline Task involvement & 6.4 & 1.6 & 3.3 & 1.0 \\
\hline Social class background & 6.8 & 1.8 & 6.7 & 1.4 \\
\hline Personality & 1.8 & 1.3 & 1.7 & 0.9 \\
\hline Human capital & 18.4 & 3.6 & 16.6 & 2.3 \\
\hline Skill requirements & 25.2 & 7.6 & 22.4 & 6.8 \\
\hline Supervisor responsibilities & 2.6 & 1.8 & 2.4 & 1.4 \\
\hline Knowledge asymmetries & 2.0 & 0.3 & 2.6 & 0.6 \\
\hline
\end{tabular}


R-squared statistics (\%)

Data: The Swedish Level-of-Living survey 2010

For operationalization see Table 1a

The results of the comparison are shown in Table 2. They show that task involvement is an intermediately strong predictor in comparison with alternative explanations of wage inequality. Task involvement explains about 6.4 percent total and 1.6 percent unique variation for men and about 3.3 percent total and 1 percent unique variation for women. The total amount of variation explained by task involvement is hence comparable to the variation explained by social class background, and larger than the total variation attributed to either personality or supervisor responsibilities or knowledge asymmetries. Similarly, the unique variation explained by task involvement is comparable to the variation independently predicted by social class background, personality and supervisor responsibilities, and larger than the variation independently attributed to knowledge asymmetries. Individual human capital and skill requirements are however clearly better predictors of wage differences than any of the other blocks. If adhering to the claimsmaking model, the most important reason for making claims on organizational wage resources is hence the possession of skills, while task involvement, personality, supervisor responsibilities and (unobserved factors related to) social class background provide some basis for such claims. Knowledge asymmetries within organizations, on the other hand, provide little basis for making claims.

\subsection{Interaction with worker autonomy}

In Table 3, we investigate whether autonomous work conditions amplifies the association between task involvement and wage attainment. Testing interactions in a small sample can be risky because interaction terms consume power due to collinearity. Therefore, in order to 
increase power, we pool results for women and men. The result confirms the expectation that worker autonomy is a general work condition that amplify the association between task involvement and wage attainment in the labor market. Task involvement is associated with a 12 percent increase in wages under the most autonomous condition, however, under the least autonomous condition the association is actually slightly negative. We interpret the finding as an indication of that task involvement yields higher wages only in work organizations that endorse workers' own initiatives in the work process. ${ }^{14}$

Table 3. Interaction analysis with worker autonomy. Men and women pooled
Task involvement
0.07
$-0.04$
$0.05,0.09$
$-0.11,0.03$
Worker autonomy
0.03
0.02
$0.02,0.05$
$0.00,0.03$
Interaction term
0.04
$0.01,0.06$

\begin{tabular}{lcc}
\hline$N$ & 1891 & 1891 \\
\hline $95 \%$ confidence intervals in second row & & \\
Data: The Swedish Level-of-Living survey 2010 & & \\
For control variables see Model 4 in Table 1a & &
\end{tabular}

\subsection{Additional analyses}

Some additional models were estimated in order to further test the robustness of the main results.

In one analysis we introduced a lagged dependent variable (LDV), occupational fixed effects, and both, to Model 4. In all of these models, the coefficient of task involvement was

\footnotetext{
${ }^{14}$ Potentially, the interaction may also reflect correlation between less autonomous work conditions and less room for individual claims-making. For instance, work in the industrial sector of the economy is often comparatively more tightly controlled by instructions and safety regulations, while wages tend to be comparatively more tied to collective bargaining agreements.
} 
substantially reduced (yet significant in all models for men); from .09 to .04 for men and from .06 to .01 for women (if we compare the most controlled model with Model 4, see table A.2 in the appendix). We suggest that two plausible explanations may account for this reduction. ${ }^{15}$

The first explanation is that certain work conditions, encouraging of the expression and maintenance of task involvement, tend to cluster in certain occupations and organizations. A question then becomes what kind of work conditions favorable for the expression and maintenance of task involvement remain after accounting for the most important factors behind worker autonomy and influence, i.e. job complexity (skill requirements) and knowledge asymmetries (monitoring difficulties and organizational importance) (see model 4 in table 1a and 1b, and also the non-interacted model including a direct measure of worker autonomy in table 3)? At least we have a hard time thinking of tasks that are generally more involving although they are equal to others in terms of how complex they are and how much task autonomy they offer. (One potential such category of tasks is artistic tasks typically performed by e.g. artists and dancers, but this is neither a very well-paid nor large enough category to influence results that much.)

Undeniably, however, explicit control variables are fallible and it is therefore also possible that occupational fixed effects and the LDV capture some aspects of the above discussed conditions that are hard to measure through a representative survey. If this explanation is correct, then we

\footnotetext{
15 Another potential explanation we do not control for is cognitive capacity (over and above what is mediated by education and skill requirements of jobs). It is not certain that individuals with a higher cognitive capacity experience more task involvement than matched individuals in equally complex jobs however. Plausibly, more intelligent individuals experience less task involvement than less intelligent individuals at the same level of task complexity because they are less challenged.
} 
estimate associations which are stronger than the individual effect of task involvement on wage attainment in the main models and come closer to the true effect in the current analysis.

The second explanation states that individuals who are motivated by task involvement select into and persist longer in high wage jobs and occupations. If this explanation is correct, occupations and previous wage attainment are located downstream of task involvement in the causal chain of events and we thus estimate associations in the current analysis that are weaker than the true effect.

Plausibly, also, both explanations may be more or less correct. In this case, the true individual effect of task involvement on wage attainment is probably located somewhere in-between the estimates in the current and the main analysis.

Unfortunately, we cannot distinguish between the two explanations given the structure of the present data. The only certain point possible to make is that the association between task interest and wages is substantial and significant also within occupations and previous wage levels. At least men motivated by task involvement, with the same occupations and previous wage attainment, still have about 4 percent higher wages than men who are motivated for other reasons (between 1 and 6 percent in the population). Increasing the level of detail in the occupational coding does not affect this interpretation. For women, the estimate in the most controlled model is about one percent and not significant.

In another supplementary analysis (included in table A.3 in the appendix), we replicated our analysis with the ESS. As far as possible, the estimation of the association between task 
involvement and wage attainment was conducted in accordance with Model $4 .{ }^{16}$ Results showed, at least for men, that the association was present also in the wider European context. Men who are motived by task involvement have about 4 percent higher wages than men who are motivated for other reasons in the European context. The coefficient for women was about 2 percent and not significant in the ESS analysis.

In general, the results in the ESS data provide less conclusive support regarding the association between task involvement and wage attainment than the analysis utilizing LNU data. There may be both methodological and substantive reasons behind this pattern. Methodological reasons include the poorer measure of wage in the ESS compared to the LNU (see section 6.1). Substantive reasons include country differences in the general quality of work, differences in the degree of unionization, and differences in skill/occupational distributions. All three of these factors may potentially affect the general degree of task complexity and worker autonomy in the labor market, and hence also the association between task involvement and wage attainment. Sweden and the Nordic countries are outstanding in the wider European context in terms of both the general quality of work, the degree of unionization, and the general skill level in the population (see e.g. Gallie 2003). Unfortunately, the fact that within-country sample sizes of fulltime employees in the ESS are quite small makes it difficult to obtain precise country-specific

\footnotetext{
${ }^{16}$ No detailed measure of parent's occupation is included in the ESS and there are no items indicating personality. These variables are hence omitted from the analysis conducted on ESS data. The measurement of the dependent variable is also different (see section: dependent variable). Supervisor responsibilities in the ESS are measured with the question "In your main job, do you have any responsibility for supervising the work of other employees?", which ranges 0 (no) - 1 (yes). Skill requirements in the ESS are measured with the questions "If someone was applying nowadays for the job you do now, would they need any education or vocational schooling beyond compulsory education" and "About how many years of education or vocational schooling beyond compulsory education would they need?”, values are 1 (Less than 1 year), 2 (about 1 year), 3 (about 2 years), 4 (about 4-5 years), 5 (about 6-7 years), 6 (about 6-7 years), 7 (about 8-9 years), 8 (10 years or more). The two variables measuring knowledge asymmetries also have different (and reversed) response values in the ESS analysis: 1 - 10, extremely difficult - extremely easy.
} 
estimates, which otherwise could have revealed such substantive differences. We do still provide an estimate from a pooled Nordic sample in table A.3 (in the appendix), which, however, is similar to estimates in the full sample. Hence, as far as we can determine with the present data, the Nordic countries are not unique in terms of the association between task involvement and wage attainment.

\section{Discussion}

This study argues that we should consider task involvement when we explain labor market inequality. From previous theory and research we have learnt that performance consequences of task involvement include work activity focus, dedication to mastery and problem-solving, and product quality perseverance. In this study of a representative labor market, we extended this argument and accounted for labor market performance/inequality in the form of wage attainment. We found that employees motivated by task involvement with the same social class background, personality, skills and job conditions still had higher wages than individuals motivated for other reasons. Estimated average wage differences are substantial: 5 - 13 percent for men and 3 - 9 percent for women in the main models, and have by all means real consequences for inequality and for the standard of living (see footnote 12). Results also showed that task involvement is of intermediate importance compared to alternative explanations of wage attainment. We additionally found that worker autonomy significantly amplified the association between task involvement and wage attainment.

This study shows the potential of introducing an exciting motivational perspective to inequality research, and situate it within a framework emphasizing how inequality emerges through relational interactions in work organizations (i.e. the claims-making model, Avent-Holt and 
Tomaskovic-Devey 2014). Needless to say, several improvements can be made in future studies located at this new cross-road between the sociology of labor markets and motivational research. First, multi-item measures are commonplace in research on task involvement, but have not been included in this or any other study that empirically analyzes labor market inequality in a representative context. Since the measure in this paper is only a binary indicator, such an inclusion would help to unravel the full thrust of motivation as an inequality generating factor. Such an approach would also allow correcting for measurement error. In addition, a panel data structure with multiple measurements of work motivation and shorter time-intervals between the surveys would help us tease out the causal relations, i.e. make us better able to statistically deal with potential (remaining) omitted variable bias and reversed causation.

In terms of theory, this study points to the limitations of considering only stable individual traits or only structural factors in inequality research. Labor market performances emerge differently depending on how individuals experience and evaluate work tasks according to a motivational perspective. Whether these performances, through an increased productivity, are materialized into objective rewards as predicted by human capital theory (Mincer 1974), depends on the ability and propensity of individuals to make claims on organizational wage resources, in competition with alternative legitimate claims (Avent-Holt and Tomaskovic-Devey 2014). In comparison with alternative claims, including skills, personality, supervisor responsibilities, knowledge asymmetries in the organization, as well as (unobserved factors related to) social class background, we showed that task involvement was an intermediately important reason. Only the possession of skills constituted a clearly more important claim than task involvement.

In terms of policy, many previous explanations of inequality tend to focus on factors that we cannot do much about subsequent to labor market entry. For instance, personality and cognitive 
capacities are formed early on in life. Consequently, interventions aimed at strengthening these traits are not that powerful if they are implemented subsequent to labor market entry (Heckman and Kautz 2012). Similarly, structural labor market inequalities are mainly explained by differences in job task complexity (Le Grand and Tahlin 2013). Task complexity is not only hard but also undesirable to change from a political point of view, because when the general complexity of work increases individuals who do not have the capacity to work in complex jobs will be excluded from the labor market. Inequality explained by task involvement is different, because it is dependent on personal evaluations of contexts and individuals evaluate contexts differently. If the individual's context changes, for instance through a worker-job match improvement, it may lead to better performance at work. Increasing worker influence in work organizations may also be helpful, but the potential effect of such a measure probably depends on whether the worker is motivated by task involvement in this kind of work in the first place. An important task for future theorizing and research is to further understand how individuals may respond differently to changes and developments in work organizations, depending on the kind of performance motivations they possess.

Policies like education and active labor market policy may help people experience task involvement in work if they are directed toward helping people attain future work they find interesting. It is however important to not conflate anticipations regarding work life and actual work motivation. Adolescents and others who have no work experience may have strong desires to achieve a certain job without having any knowledge of what it means to work in that particular occupation. Imagination and secondary information may be useful tools when people make decisions about their future work life, yet, work experience and education that includes work practices are probably better at helping individuals understand what truly motivates them at 
work. Therefore, if individuals find their chosen paths uninteresting, clear opportunities to change occupation and education subsequent to labor market entry may help them achieve better outcomes. Certainly, occupational shifts generally imply costs for both individuals and society if previous skill investments are lost, yet, this study has shown that there are costs related to not being interested in work as well.

\section{References}

Akerlof, G.A., 1982. Labor contracts as partial gift exchange. The Quarterly Journal of Economics 97, 543-569.

Akerlof, G.A., Yellen, J.L., 1986. Introduction. In: Akerlof, G. A., and Yellen, J. L., (Eds.), Efficiency wage models of the labor market. Cambridge university press, Cambridge, pp. 1-21.

Allison, P.D., 2001. Missing data. Sage publications.

Angrist, J.D., Pischke, J.-S., 2009. Parallel Worlds: Fixed Effects, Differences-in-Differences and Panel Data. In: Angrist, J. D., and Pischke, J.-S., (Eds.), Mostly harmless econometrics: an empiricist's companion. Princeton university press, Princeton, pp. 221-247.

Appelbaum, E., Bailey, T., Berg, P.B., Kalleberg, A.L., Bailey, T.A., 2000. Manufacturing advantage: Why high-performance work systems pay off. Cornell University Press.

Ariely, D., Gneezy, U., Loewenstein, G., Mazar, N., 2009. Large stakes and big mistakes. The Review of Economic Studies 76, 451-469.

Avent-Holt, D., Tomaskovic-Devey, D., 2014. A relational theory of earnings inequality. American Behavioral Scientist 58, 379-399.

Bauer, T.K., 2004. High performance workplace practices and job satisfaction: Evidence from Europe. IZA discussion paper 1265. IZA, Bonn.

Becker, G.S., 1964. Human capital. Chicago university press, Chicago.

Calder, B.J., Staw, B.M., 1975. Self-perception of intrinsic and extrinsic motivation. Journal of personality and social psychology 31, 599-605.

Cerasoli, C.P., Nicklin, J.M., Ford, M.T., 2014. Intrinsic motivation and extrinsic incentives jointly predict performance: A 40-year meta-analysis. Psychological Bulletin 140, 980-1008. 
Csikszentmihalyi, M., Csikszentmihalyi, I.S., 1992. Optimal experience: Psychological studies of flow in consciousness. Cambridge university press.

Deci, E.L., 1971. Effects of externally mediated rewards on intrinsic motivation. Journal of personality and Social Psychology 18, 105-115.

Deci, E.L., Koestner, R., Ryan, R.M., 1999. A meta-analytic review of experiments examining the effects of extrinsic rewards on intrinsic motivation. Psychological bulletin 125, 627-668.

Deci, E.L., Ryan, R.M., 2014. The importance of universal psychological needs for understanding motivation in the workplace. In: Gagné, M., (Ed.), The Oxford handbook of work engagement, motivation, and self-determination theory. Oxford University Press, New York, pp. 13-32.

Drago, F., 2011. Self-esteem and earnings. Journal of Economic Psychology 32, 480-488.

Eccles, J.S., Wigfield, A., 2002. Motivational beliefs, values, and goals. Annual review of psychology 53, 109-132.

[dataset] ESS, 2010. ESS Round 5: European Social Survey Round 5 Data. Norwegian Centre for Research Data, V3.3.

Folbre, N., 2012. Should women care less? Intrinsic motivation and gender inequality. British Journal of Industrial Relations 50, 597-619.

Gagné, M., Forest, J., Vansteenkiste, M., Crevier-Braud, L., Van den Broeck, A., 2015. The multidimensional work motivation scale: Validation evidence in seven languages and nine countries. European Journal of Work and Organizational Psychology 24, 178-196.

Gallie, D., 2003. The quality of working life: Is Scandinavia different? European Sociological Review 19, 61-79.

Gallie, D., 2013. Direct participation and the quality of work. Human Relations 66, 453-473.

Ganzeboom, H.B., Treiman, D.J., 1996. Internationally comparable measures of occupational status for the 1988 International Standard Classification of Occupations. Social science research 25, 201-239.

Glucksberg, S., 1962. The influence of strength of drive on functional fixedness and perceptual recognition. Journal of experimental psychology 63, 36-41.

Goldsmith, A.H., Veum, J.R., Darity, W., 1997. Unemployment, joblessness, psychological wellbeing and self-esteem: Theory and evidence. The Journal of Socio-Economics 26, 133-158. 
Goldthorpe, J.H., 2000. Social Class and the Differentiation of Employment Contracts. In: Goldthorpe, J. H., (Ed.), On sociology: Numbers, narratives, and the integration of research and theory. Oxford University Press, Oxford, pp. 206-229.

Haller, A.O., Portes, A., 1973. Status Attainment Processes. Sociology of Education 46, 51-91.

Harlow, H.F., 1953. Mice, monkeys, men, and motives. Psychological review 60, 23-31.

Heckman, J.J., Kautz, T., 2012. Hard evidence on soft skills. Labour economics 19, 451-464.

Homans, G.C., 1954. The cash posters: A study of a group of working girls. American Sociological Review 19, 724-733.

Hyman, H., 1953. The value systems of different classes: A social psychological contribution to the analysis of stratification. Bobbs-Merrill.

Inanc, H., Zhou, Y., Gallie, D., Felstead, A., Green, F., 2015. Direct participation and employee learning at work. Work and Occupations 42, 447-475.

Jenkins Jr, G.D., Mitra, A., Gupta, N., Shaw, J.D., 1998. Are financial incentives related to performance? A meta-analytic review of empirical research. Journal of Applied Psychology 83, 777-787.

Jirjahn, U., 2016. Performance Pay and Productivity: A Note on the Moderating Role of a Highwage Policy. Managerial and Decision Economics 37, 507-511.

Johnson, W.R., 1978. A theory of job shopping. The Quarterly Journal of Economics 92, 261278.

Jovanovic, B., 1979. Job Matching and the Theory of Turnover. Journal of Political Economy 87, 972-990.

Kalleberg, A.L., Griffin, L.J., 1978. Positional sources of inequality in job satisfaction. Work and Occupations 5, 371-401.

Kohn, M.L., Schooler, C., 1983. Work and personality: An inquiry into the impact of social stratification. Ablex Pub.

Le Grand, C., Tåhlin, M., 2013. Class, occupation, wages, and skills: The iron law of labor market inequality. In: Birkelund, G. E., and Engelstad, F., (Eds.), Class and Stratification Analysis. Emerald Group Publishing Limited, Bingley, pp. 3-46.

Lemieux, T., 2006. The “Mincer equation” thirty years after schooling, experience, and earnings. In: Grossbard, S., (Ed.), Jacob Mincer A Pioneer of Modern Labor Economics. Springer, Boston, MA, pp. 127-145. 
Lepper, M.R., Greene, D., Nisbett, R.E., 1973. Undermining children's intrinsic interest with extrinsic reward: A test of the "overjustification" hypothesis. Journal of Personality and social Psychology 28, 129.

Lindqvist, E., Vestman, R., 2011. The labor market returns to cognitive and noncognitive ability: Evidence from the Swedish enlistment. American Economic Journal: Applied Economics 3, 101128.

[dataset] LNU, 2000, 2010. Levnadsnivåundersökningen (The Swedish Level-of-Living Survey) 2000 and 2010. The Swedish Institute for Social Research (SOFI).

Mason, W., Watts, D.J., 2010. Financial incentives and the performance of crowds. ACM SigKDD Explorations Newsletter 11, 100-108.

Mincer, J., 1974. Schooling, Experience, and Earnings. Human Behavior \& Social Institutions No. 2. NBER.

Nicholls, J.G., 1984. Achievement motivation: Conceptions of ability, subjective experience, task choice, and performance. Psychological review 91, 328-346.

Nye, C.D., Su, R., Rounds, J., Drasgow, F., 2012. Vocational interests and performance a quantitative summary of over 60 years of research. Perspectives on Psychological Science 7, 384-403.

Nyhus, E.K., Pons, E., 2005. The effects of personality on earnings. Journal of Economic Psychology 26, 363-384.

Parsons, T., 1940. An analytical approach to the theory of social stratification. American Journal of Sociology 45, 841-862.

Peach, E.K., Stanley, T.D., 2009. Efficiency Wages, Productivity and Simultaneity: A MetaRegression Analysis. Journal of Labor Research 30, 262-268.

Rammstedt, B., John, O.P., 2007. Measuring personality in one minute or less: A 10-item short version of the Big Five Inventory in English and German. Journal of research in Personality 41, 203-212.

Ryan, R.M., Deci, E.L., 2000. Intrinsic and extrinsic motivations: Classic definitions and new directions. Contemporary educational psychology 25, 54-67.

Schwartz, S.H., Bilsky, W., 1987. Toward a universal psychological structure of human values. Journal of personality and social psychology 53, 550.

Shanahan, M.J., Bauldry, S., Roberts, B.W., Macmillan, R., Russo, R., 2014. Personality and the Reproduction of Social Class. Social Forces 93, 209-240. 
Spenner, K.I., Featherman, D.L., 1978. Achievement ambitions. Annual review of sociology, 373-420.

StataCorp, 2013. Stata Statistical Software: Release 13. StataCorp LP, College Station, TX.

Tahlin, M., 2016. Money, monitoring and motivation: Social class and work effort. Presentation at the annual meeting for the Society for the Advancement of Socio-Economics. (SASE), Berkely, California, June 24-26.

Von Hippel, P.T., 2007. Regression with Missing Ys: An Improved Strategy for Analyzing Multiply Imputed Data. Sociological Methodology 37, 83-117.

White, R.W., 1959. Motivation reconsidered: The concept of competence. Psychological review 66, 297-333.

Williams, M.L., McDaniel, M.A., Nguyen, N.T., 2006. A meta-analysis of the antecedents and consequences of pay level satisfaction. Journal of Applied Psychology 91, 392-413. 


\section{Appendix}

Table A.1a. Descriptive statistics. The Swedish Level-of-Living survey (2000-2010)

\begin{tabular}{|c|c|c|c|c|}
\hline & $\mathrm{N}$ & $\begin{array}{l}\text { Mean / \% } \\
\text { Yes }\end{array}$ & SD & $\begin{array}{l}\text { Missing } \\
\text { (imputed) }\end{array}$ \\
\hline Gender = Woman & 1891 & $48.44 \%$ & & \\
\hline Age & 1891 & 46.79 & 9.69 & \\
\hline Hourly wage & 1891 & 176.79 & 66.74 & \\
\hline Task involvement & 1872 & $46.85 \%$ & & 19 \\
\hline Worker autonomy & 1890 & 3.75 & 0.95 & 1 \\
\hline Parents' SIOPS & 1803 & 43.48 & 12.27 & 88 \\
\hline Agreeableness & 1702 & 3.65 & 0.61 & 189 \\
\hline Conscientiousness & 1718 & 3.92 & 0.66 & 173 \\
\hline Extraversion & 1702 & 3.66 & 0.80 & 189 \\
\hline Neuroticism & 1715 & 2.38 & 0.79 & 176 \\
\hline Openness & 1702 & 3.16 & 0.96 & 189 \\
\hline Years of schooling & 1891 & 13.85 & 3.13 & \\
\hline Work experience & 1886 & 24.45 & 10.97 & 5 \\
\hline Skill requirements & 1877 & 3.87 & 2.83 & 14 \\
\hline Supervisor responsibilities & 1884 & 7.88 & 61.87 & 7 \\
\hline Organizational importance & 1884 & 3.43 & 0.99 & 7 \\
\hline Monitoring difficulties & 1835 & 2.83 & 1.13 & 56 \\
\hline Hourly wage 2000 & 1449 & 117.69 & 45.68 & 442 \\
\hline Earnings 2000 (000s) & 1891 & 2074.78 & 1402.64 & \\
\hline Legislator/official & 1879 & $0.11 \%$ & & 12 \\
\hline Corporate man. & 1879 & $6.01 \%$ & & 12 \\
\hline General man. & 1879 & $0.59 \%$ & & 12 \\
\hline Science/tech. prof. & 1879 & $6.71 \%$ & & 12 \\
\hline Health prof. & 1879 & $2.61 \%$ & & 12 \\
\hline Teaching prof. & 1879 & $6.81 \%$ & & 12 \\
\hline Other prof. & 1879 & $10.11 \%$ & & 12 \\
\hline Science/tech. ass. prof. & 1879 & $8.36 \%$ & & 12 \\
\hline Health ass. prof. & 1879 & $3.51 \%$ & & 12 \\
\hline Teaching ass. prof. & 1879 & $3.41 \%$ & & 12 \\
\hline Other ass. prof. & 1879 & $11.44 \%$ & & 12 \\
\hline Office clerk & 1879 & $5.48 \%$ & & 12 \\
\hline Customer serv. & 1879 & $0.90 \%$ & & 12 \\
\hline Personal serv. & 1879 & $11.66 \%$ & & 12 \\
\hline Salesperson & 1879 & $2.08 \%$ & & 12 \\
\hline Skilled agricultural & 1879 & $0.59 \%$ & & 12 \\
\hline
\end{tabular}




\begin{tabular}{|c|c|c|c|c|}
\hline Extraction/construction & 1879 & $3.67 \%$ & & 12 \\
\hline Metal & 1879 & $2.77 \%$ & & 12 \\
\hline Handicrafts & 1879 & $0.59 \%$ & & 12 \\
\hline Other craft & 1879 & $0.37 \%$ & & 12 \\
\hline Plant operator & 1879 & $1.38 \%$ & & 12 \\
\hline Operator/assembler & 1879 & $4.26 \%$ & & 12 \\
\hline Driver & 1879 & $3.19 \%$ & & 12 \\
\hline El. service/sales & 1879 & $3.14 \%$ & & 12 \\
\hline Laborer & 1879 & $0.27 \%$ & & 12 \\
\hline Task involvement score & 1872 & 0.33 & 0.38 & 19 \\
\hline Accomplishment score & 1872 & 0.66 & 0.39 & 19 \\
\hline Keep the job score & 1872 & 0.08 & 0.23 & 19 \\
\hline Job is useful to others score & 1872 & 0.33 & 0.40 & 19 \\
\hline Wages/Promotion score & 1872 & 0.05 & 0.17 & 19 \\
\hline Duty score & 1872 & 0.05 & 0.20 & 19 \\
\hline
\end{tabular}

Statistics refer to 2010 if otherwise not specified 
Table A.1b. Descriptive statistics. The European Social Survey (2010)

\begin{tabular}{|c|c|c|c|}
\hline & $\mathrm{N}$ & Mean / \% Yes & SD \\
\hline Gender $=$ Woman & 6257 & $50.39 \%$ & \\
\hline Task involvement & 6257 & $29.39 \%$ & \\
\hline Years of schooling & 6257 & 14.67 & 3.49 \\
\hline Work experience & 6257 & 22.66 & 10.22 \\
\hline Skill requirements & 6257 & 4.33 & 1.78 \\
\hline Monitoring difficulties & 6257 & 7.11 & 2.38 \\
\hline Organizational importance & 6257 & 5.57 & 2.65 \\
\hline Supervisor responsibilities & 6257 & $36.36 \%$ & \\
\hline Legislator/Manager unspec. & 6257 & $0.06 \%$ & \\
\hline Legislator/official & 6257 & $0.24 \%$ & \\
\hline Corporate man. & 6257 & $7.91 \%$ & \\
\hline General man. & 6257 & $1.50 \%$ & \\
\hline Professional unspec. & 6257 & $0.08 \%$ & \\
\hline Science/tech. prof. & 6257 & $5.69 \%$ & \\
\hline Health prof. & 6257 & $3.34 \%$ & \\
\hline Teaching prof. & 6257 & $9.89 \%$ & \\
\hline Other prof. & 6257 & $8.26 \%$ & \\
\hline Ass. prof. unspec & 6257 & $0.03 \%$ & \\
\hline Science/tech. ass. prof. & 6257 & $5.18 \%$ & \\
\hline Health ass. prof. & 6257 & $4.86 \%$ & \\
\hline Teaching ass. prof. & 6257 & $2.33 \%$ & \\
\hline Other ass. prof. & 6257 & $10.95 \%$ & \\
\hline Clerk unspec. & 6257 & $0.16 \%$ & \\
\hline Office clerk & 6257 & $7.94 \%$ & \\
\hline Customer serv. & 6257 & $1.29 \%$ & \\
\hline Service and sales unspec. & 6257 & $0.16 \%$ & \\
\hline Personal serv. & 6257 & $7.94 \%$ & \\
\hline Salesperson & 6257 & $2.91 \%$ & \\
\hline Skilled agricultural & 6257 & $0.46 \%$ & \\
\hline Crafts unspec. & 6257 & $0.06 \%$ & \\
\hline Extraction/construction & 6257 & $3.23 \%$ & \\
\hline Metal & 6257 & $4.92 \%$ & \\
\hline Handicrafts & 6257 & $0.40 \%$ & \\
\hline Other craft & 6257 & $1.36 \%$ & \\
\hline Operator / assembler unspec. & 6257 & $0.08 \%$ & \\
\hline Plant operator & 6257 & $0.83 \%$ & \\
\hline Operator/assembler & 6257 & $1.65 \%$ & \\
\hline Driver & 6257 & $3.69 \%$ & \\
\hline Elementary unspec. & 6257 & $0.03 \%$ & \\
\hline
\end{tabular}




\begin{tabular}{|c|c|c|}
\hline El. service/sales & 6257 & $1.60 \%$ \\
\hline Agricultural laborer & 6257 & $0.08 \%$ \\
\hline Laborer & 6257 & $0.86 \%$ \\
\hline Belgium & 6257 & $3.87 \%$ \\
\hline Bulgaria & 6257 & $3.84 \%$ \\
\hline Switzerland & 6257 & $3.96 \%$ \\
\hline Cyprus & 6257 & $0.74 \%$ \\
\hline Czechia & 6257 & $3.40 \%$ \\
\hline Germany & 6257 & $6.81 \%$ \\
\hline Denmark & 6257 & $6.11 \%$ \\
\hline Estonia & 6257 & $3.55 \%$ \\
\hline Spain & 6257 & $2.59 \%$ \\
\hline Finland & 6257 & $6.20 \%$ \\
\hline France & 6257 & $5.37 \%$ \\
\hline United Kingdom & 6257 & $4.44 \%$ \\
\hline Greece & 6257 & $1.98 \%$ \\
\hline Croatia & 6257 & $1.57 \%$ \\
\hline Hungary & 6257 & $3.24 \%$ \\
\hline Ireland & 6257 & $3.07 \%$ \\
\hline Israel & 6257 & $2.76 \%$ \\
\hline Lithuania & 6257 & $1.57 \%$ \\
\hline Netherlands & 6257 & $5.05 \%$ \\
\hline Norway & 6257 & $7.46 \%$ \\
\hline Poland & 6257 & $3.05 \%$ \\
\hline Portugal & 6257 & $0.62 \%$ \\
\hline Russia & 6257 & $4.49 \%$ \\
\hline Sweden & 6257 & $6.62 \%$ \\
\hline Slovenia & 6257 & $2.78 \%$ \\
\hline Slovakia & 6257 & $2.97 \%$ \\
\hline Ukraine & 6257 & $1.89 \%$ \\
\hline
\end{tabular}


Table A.2. Regression of logged hourly wage on task involvement including previous wage attainment and occupational fixed effects as additional controls.

Occ. fixed effects LDV

For men:

Occ. fixed effects

Both

Task involvement
0.05
0.05
0.04
$0.01,0.08$
$0.02,0.09$
$0.01,0.06$

\begin{tabular}{lccc}
\hline$N$ & 975 & 975 & 975 \\
\hline For women: & & & \\
Task involvement & 0.03 & 0.03 & 0.01 \\
& $-0.00,0.05$ & $-0.00,0.05$ & $-0.02,0.04$ \\
\hline$N$ & & & 916 \\
\hline
\end{tabular}

95\% confidence intervals in second row

Data: The Swedish Level-of-Living survey 2000-2010; For other control variables see model 4 in table 1a

Table A.3. Regression of logged hourly wage on task involvement with the European Social Survey

\begin{tabular}{lccc}
\hline & Men & Women & Nordic countries \\
\hline Task involvement & 0.04 & 0.02 & 0.03 \\
& $0.01,0.06$ & $-0.00,0.04$ & $-0.00,0.06$ \\
Years of schooling & 0.02 & 0.01 & 0.01 \\
& $0.01,0.02$ & $0.01,0.02$ & $0.00,0.01$ \\
Work experience & 0.01 & 0.01 & 0.01 \\
& $0.01,0.02$ & $0.01,0.02$ & $0.00,0.01$ \\
Work experience & -0.00 & -0.00 & -0.00 \\
squared & $-0.00,-0.00$ & $-0.00,-0.00$ & $-0.00,0.00$ \\
Skill requirements & 0.05 & 0.04 & 0.07 \\
& $0.04,0.06$ & $0.03,0.04$ & $0.06,0.08$ \\
Monitoring & -0.00 & -0.00 & -0.00 \\
difficulties & $-0.01,0.00$ & $-0.01,0.00$ & $-0.01,0.01$ \\
Organizational & -0.00 & -0.00 & 0.00 \\
importance & $-0.01,0.00$ & $-0.01,0.00$ & $-0.00,0.01$ \\
Supervisor & 0.05 & 0.06 & 0.10 \\
responsibilities & $0.03,0.08$ & $0.04,0.09$ & $0.07,0.13$ \\
\hline$N$ & 3130 & 3166 & 1658 \\
\hline
\end{tabular}

95\% confidence intervals in second row

Data: The European Social Survey 2010; All models are estimated with country dummies and robust standard errors 
Table A.4. Regression of logged hourly wage on alternative specification of task involvement in reference to various other motivations

\begin{tabular}{lcc}
\hline & Men & Women \\
\hline Task involvement (omitted) & & \\
Comparison work & & \\
motivations: & & \\
Accomplishment & -0.07 & -0.07 \\
& $-0.13,-0.02$ & $-0.12,-0.02$ \\
Financial & -0.11 & -0.08 \\
& $-0.20,-0.01$ & $-0.20,0.03$ \\
Keep the job & -0.16 & -0.08 \\
& $-0.23,-0.08$ & $-0.16,-0.00$ \\
Job is useful for others & -0.13 & -0.11 \\
& $-0.19,-0.08$ & $-0.15,-0.07$ \\
Duty & -0.11 & -0.07 \\
& $-0.20,-0.02$ & $-0.16,0.01$ \\
\hline$N$ & & 916 \\
\hline $95 \%$ confidence ing
\end{tabular}

95\% confidence intervals in second row

Data: The Swedish Level-of-Living survey 2010

For control variables see model 4 in table 1a

Table A.5. Regression of logged hourly wage on task involvement. Case-wise exclusion instead of multiple imputation

\begin{tabular}{lcc}
\hline & Men & Women \\
\hline Task involvement & 0.08 & 0.06 \\
& $0.04,0.12$ & $0.02,0.09$ \\
\hline$N$ & 780 & 764 \\
\hline
\end{tabular}

95\% confidence intervals in second row

Data: The Swedish Level-of-Living survey 2010

For control variables see model 4 in table $1 \mathrm{a}$ 